Revista Chilena de Antropología $\mathrm{N}^{*} 5,1986,11-16$

Faccultad de Filosofía, Humanidades y Educación

liniversidad de Chile, Santiago, Chile

\title{
Punta Cola de Pescado encontrada en Chile Central
}

\author{
Jorge Kaltwasser, Alberto Medina, \\ Eugenio Aspillaga e Iván Cáceres
}

En Santa Inés se encontró la base de una punta de proyectil acanalada del tipo "Cola de Pescado". Esta localidad está situada en la margen Norte de la ex Laguna de Tagua-Tagua, a 4 km de Cuchipuy y 11 de la Comuna de San Vicente de Tagua-Tagua, en la zona central de Chile. La ex Laguna ha sido una región a menudo estudiada por la Paleontología desde años atrás y ahora por la Arqueología en forma metódica y más intensa. Montané (1968), Núñez (m.s.) y nosotros (1980) hemos postulado diversos niveles ocupacionales tempranos, estudios que deben continuarse, para escribir la historia de la ocupación humana de estos lugares a través de 11000 años antes del presente o más.

El sitio arqueológico que se encuentra en Santa Inés está notablemente disturbado, debido a actividades humanas pasadas y presentes. Desde ya podemos mencionar el camino vecinal que prácticamente divide en dos el área de las excavaciones; una plantación de olivos desaparecida y el natural crecimiento de espinos, a lo que debe agregarse antiguas delimitaciones de propiedades, que se verifican en las improntas de los postes de cercados y, para terminar, la instalación a un metro de profundidad de una cañería que arrasó parte importante de los materiales arqueológicos.

Santa Inés presenta dos niveles ocupacionales dispuestos en posición estratigráfica: a) Bajo una débil capa vegetal de $30 \mathrm{~cm}$ de espesor se encuentran fragmentos de cerámica burda en asociación con manos de moler y restos de animales pequeños. Hasta ahora no ha sido posible obtener una muestra confiable de carbón para realizar un fechado de C 14, sin embargo pensamos que puede tener una antigüedad cercana a los 1000 años antes del presente; b) A partir de los $30 \mathrm{~cm}$ aparece un segundo nivel que alcanza aproxidamente $70 \mathrm{~cm}$ de profundidad. Se caracteriza en especial por la presencia de entierros humanos, en tumbas muy disturbadas, asociados con puntas de proyectil triangulares, 
manos de moler, piedras horadadas y fogones. Este nivel se fechó por C 14 en $3720 \pm 100$ años A.P.

Como se ha señalado, en Santa Inés, en una de las cuadrículas se recuperó la base de un instrumento muy diferente al resto de los encontrados en el sitio y en la mayor parte del territorio nacional. Se trata del fragmento proximal de una punta de proyectil acanalada del tipo "Cola de Pescado". La pieza se encontró a $80 \mathrm{~cm}$ de profundidad y $15 \mathrm{~cm}$ bajo el piso de una tumba localizada a $90 \mathrm{~cm}$ en dirección Este. El estrato geológico en el que estaba corresponde a una arcilla café-amarillenta muy dura y con escasa presencia de clastos medianos a pequenoos. Aunque se tuvo un cuidado extremo en el proceso de su extraccción y harneo posterior no aparecieron otros indicadores arqueológicos que permitieran definir mejor su contexto asociado.

\section{DESCRIPCIÓN}

La pieza está confeccionada en andesita de color gris oscuro. En la cuenca de la ex Laguna de Tagua-Tagua no se han localizado yacimientos de este tipo de piedra, siendo, al parecer, la cordillera andina de la región la parte más cercana donde podría encontrarse. (Ver fotos). A pesar de que tenemos un ejemplar incompleto, seguiremos las normas propuestas por Bird (1969) para conocer el grado de similitud de esta pieza con las puntas "Cola de Pescado" descritas para Chile y Ecuador. Este método ya fue utilizado por Ossa (1975) para describir su ejemplar recolectado en Perú.

Las medidas son:

Largo: $17 \mathrm{~mm}$

Ancho mínimo: $14 \mathrm{~mm}$

Espesor máximo $5 \mathrm{~mm}$

Distancia máxima entre las esquinas del pedúnculo: $19 \mathrm{~mm}$

Similitud 1: Naturaleza del sitio.

Es imposible determinar la función del sitio a partir de un ejemplar único. Por tanto la similitud no puede ser comprobada. En todo caso es necesario aclarar que en Santa Inés hay dos niveles ocupacionales, en los cuales la función es fácilmente identificable. Aquí nos referimos tan sólo al nivel en el cual apareció la pieza, el que, aparentemente, no tiene relación directa con los niveles citados.

Similitud 2: Manufactura uno.

Puesto que falta la mayor parte de la hoja es imposible establecer esta similitud, que se refiere a la preparación de la hoja.

Similitud 3: Manufactura dos (Acanaladura).

La parte basal o pedúnculo se encuentra acanalada en ambas caras. Una clara similitud con algunas piezas del tipo descrito por Bird.

Similitud 4: Manufactura tres (Pulimento de los bordes).

El pulimento marginal de los bordes del pedúnculo ocurre en toda su extensión y 


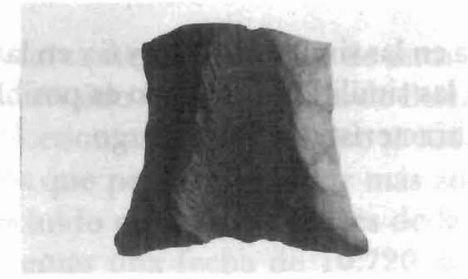

Cara dorsal

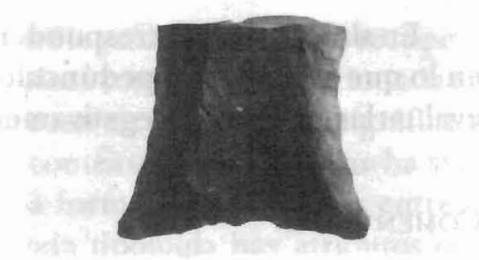

Cara ventral

Fragmento de punta "Cola de Pescado" de Santa Inés

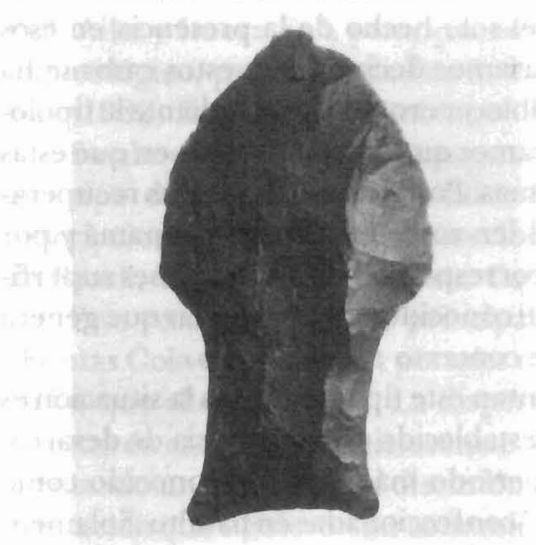

Cara dorsal

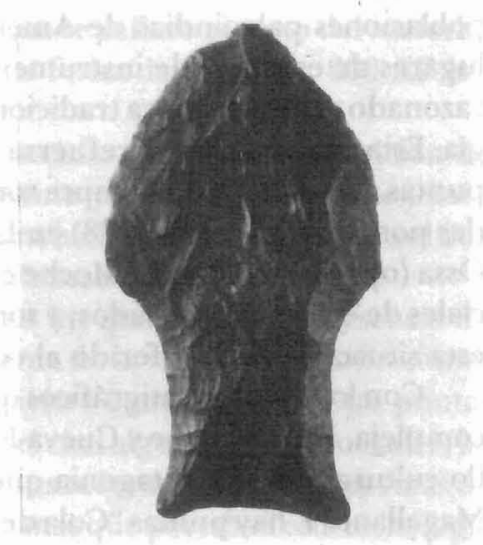

Cara ventral

Punta "Cola de Pescado" recuperada por Bird en Cueva Fell (Gentileza Museo Nacional de Historia Natural)

se puede advertir por simple contacto. Las trazas de la dirección del movimiento que provocó este trabajo son difíciles de identificar. Una nueva identidad con las normas propuestas.

\section{Similitud 5: Forma.}

No se puede establecer la similitud de la forma de la hoja, por cuanto falta la mayor parte de ella, no obstante, la similitud es completa en la forma de pedúnculo; éste disminuye gradualmente hacia una base cóncava y sus lados tienden a ser cóncavos.

Similitud 6: Tipo de Fractura.

La pieza está quebrada trasversalmente, hacia la parte más estrecha del pedúnculo. Una nueva similitud con los ejemplares de Ecuador y Sur de Chile. 
En síntesis, hay correspondencia completa en las similitudes 3,4 y 6 y en la 5 en lo que se refiere al pedúnculo. Respecto a las similitudes 1 y 2 no es posible evaluarlas positiva o negativamente por las características del hallazgo.

\section{Comentario}

A partir de los trabajos de Bird en la Patagonia se ha generalizado la idea de que las puntas "Cola de Pescado" son "marcadoras" de sitios paleoindios. Si bien en Palli Aike y Cueva Fell la asociación con fauna extinta es indiscutible, avalada además por fechados radiocarbónicos que confirman la antigüedad de los hallazgos, al parecer en otros sitios se ha procedido con cierta prisa al asignarlos a las poblaciones paleoindias de América por el solo hecho de la presencia en esos lugares de este tipo de instrumentos. Podríamos decir que en estos casos se ha razonado de una manera tradicional al establecer cronologías mediante la tipología. Esta aprehensión se refuerza si observamos que las condiciones en que estas puntas se recobran no siempre son las óptimas. Por ejemplo, las piezas recuperadas por Bird y Cooke (1978) en Lago Madden zona del Canal de Panamá y por Ossa (op. cit.) en el Valle Moche en Perú, corresponden a recolecciones superficiales de ejemplares aislados; y son bastante conocidos los problemas que genera esta situación en lo referido al control de contexto arqueológico.

Con los sitios estratigráficos que presentan este tipo de puntas la situación es compleja. En Palli Aike y Cueva Fell se ha establecido una secuencia de desarrollo cultural para la Patagonia que en su período más antiguo, conocido como Magallanes I, hay puntas "Cola de Pescado" confeccionadas en basalto. Solamente algunas piezas presentan acanaladura en la sección proximal. Se encuentran asociadas a restos óseos humanos y a fauna extinta y actual: caballo americano, milodon, guanaco y felinos. Los sitios han sido fechados por C 14 en $10.720 \pm$ 300 y $11.000 \pm 170$ para la Cueva Fell y en $8.639 \pm 450$ AP para Palli Aike.

En el caso de El Inga en Ecuador la situación es un tanto diferente. Aunque allí se hizo una excavación estratigráfica ella se realizó una vez que la recolección superficial del sitio apor tó la casi totalidad de las puntas. Por otro lado la misma estratigrafía es difusa, puesto que la superficie soporta una erosión muy intensa tanto por las lluvias como por el arado, que incluso en algunos sectores del sitio se llevó el suelo superficial. Bajo este suelo, en un estrato muchas veces expuesto, se encontró la mayor parte de los instrumentos, que estaban confeccionados en obsidiana (cf. Mayer-Oakes 1963, 1966). Los antecedentes que han permitido asociar a El Inga con el poblamiento temprano de América corresponden a la fecha de 9.030 \pm 144 AP y a la similitud tipológica con las puntas de la Patagonia. La situación ya descrita para este sitio permite decir que "Por desgracia, la datación... no tiene bases geocronológicas muy firmes, pues el terreno en general está muy erosionado y sin vinculación con fenómenos glaciales o volcánicos..." (Schobinger 1969: 115).

En Argentina se han localizado puntas "Cola de Pescado" en varios lugares. 
Aquí comentaremos dos de estos hallazgos, Nora Flegenheimer (1980) recuperó de un sitio de la provincia de Buenos Aires una pieza completa confeccionada en calcedonia. En el nivel que se recuperó no aparecen otros elementos significativos que permitan definir más adecuadamente contexto. Este ejemplar ha sido incluido en el tipo a través de la categoria de la forma. La autora nos entrega además una fecha de $10.720 \pm 150 \mathrm{AP}$. En toda tipologia hay atributos que presentan algunas variaciones significativas. La libertad que emana de esas variaciones permite incluir ciertas piezas de Los Toldos (extremo sur argentino) dentro del tipo. Aunque no todos los autores se convencen de que esas piezas correspondan efectivamente a las que comentamos, se debe señalar que aparte de esta situación poco clara, Los Toldos comparte importantes similitudes con Palli Aike y Cueva Fell, principalmente en lo que se refiere al resto del material arqueológico, presencia de fauna extinta y una fecha de $12.600 \pm 600 \mathrm{AP}$ (cf. Bate 1982; Bird 1970; Schobinger 1973).

Finalmente, debemos consignar algunas noticias acerca de la aparición de este tipo de puntas en otros sitios del continente y de las cuales no tenemos descripciones detalladas, tales son los casos de los hallazgos señalados para el Sur de Brasil, Uruguay, Costa Rica, Colombia y Venezuela.

Este recorrido por los principales sitios en los que ocurre la presencia de "Puntas Cola de Pescado", permite darnos cuenta de la variedad de condiciones en las que ellas aparecen. La dispersión en nuestro continente de estas puntas insertas en el contexto pleistocénico tardío con el cual algunas están asociadas, ha planteado una importante discusión acerca de sus orígenes y las posibles rutas de migración que siguieron las comunidades humanas que portaban esta tecnología lítica en su poblamiento de Sudamérica. La acanaladura presente en un número significativo de las puntas descritas ha generado interesantes especulaciones en torno a su vinculación con los instrumentos Clovis de Norteamérica, reforzadas por la presencia en Guatemala del fragmento basal de una punta Clovis que se sacó en un nivel fechado $10.720 \pm 170$ A.P. (Gruhn y Bryan 1977). Sin embargo la presencia de las puntas "Cola de Pescado" en diferentes contextos ha complicado el poder establecer con mayor grado de seguridad rutas definidas de este poblamiento para Sudamérica.

A nuestro juicio las implicaciones del hallazgo de un fragmento de punta de proyectil acanalada "Cola de Pescado" en Santa Inés, a $80 \mathrm{~cm}$ de profundidad de un terreno plano, son las siguientes:

1. Hemos podido definir con seguridad que nuestro ejemplar corresponde efectivamente al tipo descrito para el Sur de Chile y Ecuador.

2. Aunque existe una similitud morfológica con las piezas señaladas, la falta de un contexto arqueológico mejor definido impide adscribir con seguridad este ejemplar a un contexto pleistocénico tardio.

3. También se podrá pensar en una supervivencia de esta tradición tecnológica, puesto que se encuentra en sitios de cazadores especializados del Paleoindio como la cueva de Fell y Palli Aike y por tanto sería posible su presencia en 
otros sitios más tardíos correspondientes a una economía arcaica de caza y recolección.

4. La consecuencia más importante de este hallazgo es situar a la cuenca de la ex Laguna de Tagua-Tagua en un lugar de relevancia de los movimientos migratorios de las comunidades portadoras de esta tradición tecnológica, y sus vinculaciones con otros sitios de la región central de Chile, donde todavía no se encuentran estos artefactos.

5. Finalmente este hallazgo confirma la importancia que tiene para la investigación arqueológica en América la ex Laguna de Tagua-Tagua, especialmente para un mejor conocimiento de los grupos humanos representados por los períodos Paleoindio y Arcaico.

\section{Bibliografía}

Bate, Luis Felipe. Origenes de la comunidad primitiva en Patagonia. México. Ediciones Cuicuilco. 1982.

Bird, Junius. "A comparision of South Chilean and Ecuatorian "fishtail" projectile points". The Kroeber Anthropological Society Papers, No 40 [Berkeley], 1969, pp. 52-71.

Bird, Junius. Paleo Indian Discoidal Stones from Southern South America. American Antiquity, Volumen 35, 1970, pp. 205-209.

BiRd, Junius y Richard CoOKE. "The ocurrence in Panama of two types of Paleo-Indians projectile points". En: Early Man in America from a Circum-Pacific Perspective: Canadá, Alan Lyle Bryan (ed.). Ocasional Papers $\mathrm{N}^{\circ} 1$ of the Department of Anthropology. University of Alberta, I978, pp. 263-272.

Flegenheimer, Nora. "Hallazgos de Puntas Cola de Pescado en la Provincia de Buenos Aires". Relaciones de la Sociedad Argentina de Antropologí. Tomo XIV No 1 [Buenos Aires] 1980, pp. 169-176.

Kaltwasser, Jorge; Medina, Alberto y Munizaga, Juan. Cementerio del Periodo Arcaico en Cuchipuy. Revista Chilena de Antropología, No 3. [Santiago]. Editorial Universitaria. 1980, pp. I09-122.

Mayer-Oakes, William. "Early Man in the Andes". Scientific American [Nueva York]. Volumen 208, 1963, pp. 53-61.

MAYer-OAKes, William. El Inga projectile points -surface collections. American Antiquity. Volumen 31, 1966, pp. 644-661.

Montane, Julıo. Primera fecha radiocarbónica de Tagua-Tagua, Santiago Noticiario Mensual $N^{\circ} 139$ del Museo Nacional de Historia Natural. 1968.

Ossa, Paul. A fluted "fishtail" projectile point from La Cumbre, Moche Valley, Perú. [Berkeley] Nawpa Pacha No 13,1975 , pp. 97-99.

Schobinger, Juan. Prehistoria de Suramérica. Barcelona. Editorial Labor, 1969.

SChobinber, Juan. Nuevos hallazgos de puntas "colas de pescado", y consideraciones en torno al origen y dispersión de la cultura de cazadores superiores toldense (Fell I) en Sudamérica. XL Congreso Internacional de Americanistas (Roma 1972), Tomo I, Génova, 1973. 